MISS CHRISTINE GAYAN LI (Orcid ID : 0000-0001-9098-0505)

Article type : Case Report

Dexmedetomidine Infusion Overdose during Anaesthesia: A Case

$\underline{\text { Report }}$

Christine $\mathrm{Li}^{1}$ and Michael Clifford ${ }^{2}$

1. University of Melbourne, Parkville, VIC

2. Department of Anaesthesia and Pain Management, Royal Children's Hospital, Parkville, VIC

\title{
Correspondence:
}

\section{Michael Clifford}

The Royal Children's Hospital Melbourne

50 Flemington Road

Parkville, VIC 3052

Email: michael.clifford@rch.org.au

Short Title: Dexmedetomidine Overdose

Article Category: Case report

\section{Summary}

A $12 \mathrm{~kg}$ infant was given intravenous dexmedetomidine $0.2 \mu \mathrm{g} \cdot \mathrm{kg}^{-1} \cdot \mathrm{min}^{-1}$ as an adjunct for general anaesthesia. The 60 -fold increase in dexmedetomidine infusion rate caused a biphasic response with initial hypertension followed by bradycardia and This is the author manuscript accepted for publication and has undergone full peer review but has not been through the copyediting, typesetting, pagination and proofreading process, which may lead to differences between this version and the Version of Record. Please cite this article as doi: 10.1111/PAN.13801

This article is protected by copyright. All rights reserved 
hypotension requiring inotropic support. No postoperative or long-term sequelae were noted. Dexmedetomidine infusion is usually delivered as $\mu \mathrm{g} \cdot \mathrm{kg}^{-1} \cdot \mathrm{h}^{-1}$.

\section{Keywords}

medication error, adverse effect, pharmacokinetics, pharmacodynamics

\section{Introduction}

Dexmedetomidine is a selective alpha2-receptor antagonist used intraoperatively as an adjunct for general anaesthesia. Dexmedetomidine has the infusion regimen of $\mu \mathrm{g} \cdot \mathrm{kg}^{-1} \cdot \mathrm{h}^{-1}$, rather than the common infusion regimen of $\mu \mathrm{g} \cdot \mathrm{kg}^{-1} \cdot \mathrm{min}^{-1}$. This produces potential for error, where previous overdoses have been reported ${ }^{1,2}$. There are few reports describing dexmedetomidine infusions administered at 60-times the intended rate for an extended period of time in infants.

\section{Case Report}

A $12 \mathrm{~kg}, 23$-month-old male, ASA III, with a history of tuberous sclerosis presented for neurosurgery and magnetic resonance imaging (MRI). A review of systems revealed mild left hemiplegia, cardiac tumours, cystic kidney disease, renal angiomyolipomas and retinal hamartomas. The infant presented in a calm, non-agitated state, with heart rate (HR) $109 \mathrm{bpm}$ and blood pressure (BP) 113/79 mmHg. Dexmedetomidine $12 \mu \mathrm{g}$ was administered as premedication.

The infant underwent sevoflurane induction with atracurium $6 \mathrm{mg}$, remifentanil $10 \mu \mathrm{g}$ and dexamethasone $8 \mathrm{mg}$. The procedure involved two stages; MRI followed by surgery. Anaesthesia during MRI was maintained with sevoflurane. Anaesthesia during the operative stage initially involved remifentanil $0.2 \mu \mathrm{g} \quad \mathrm{kg}^{-1} \cdot \mathrm{min}^{-1}$ and dexmedetomidine $0.2 \mu \mathrm{g} . \mathrm{kg}^{-1} \cdot \mathrm{min}^{-1}$. The incorrect rate of dexmedetomidine infusion was an unnoticed pump programming error, where the intended infusion rate was 2.0 $\mu \mathrm{g} \cdot \mathrm{kg}^{-1} \cdot \mathrm{h}^{-1}$.

The infant was initially hypertensive at $130 / 80 \mathrm{mmHg}$. After 100 minutes of dexmedetomidine infusion, a decline in HR and BP were noted (Figure 1a). Dexmedetomidine was decreased to $0.1 \mu \mathrm{g} \cdot \mathrm{kg}^{-1} \cdot \mathrm{min}^{-1}$. It was a further 20 minutes 
before the dexmedetomidine infusion was ceased and anaesthesia continued with isoflurane. Epinephrine $0.05 \mu \mathrm{g} \cdot \mathrm{kg}^{-1} \cdot \mathrm{min}^{-1}$ was commenced and propofol $40 \mathrm{mg}$ administered. Although the infant's HR increased to $110 \mathrm{bpm}$, BP persisted at 80/30 mmHg. Remifentanil was reduced to $0.1 \mu \mathrm{g} \cdot \mathrm{kg}^{-1} \cdot \mathrm{min}^{-1}$ and norepinephrine $0.05 \mu \mathrm{g} . \mathrm{kg}^{-}$ ${ }^{1} . \mathrm{min}^{-1}$ was commenced. Additional analgesics, paracetamol $180 \mathrm{mg}$ and fentanyl $20 \mu \mathrm{g}$ were administered. A total of $750 \mathrm{~mL}$ of balanced crystalloid was delivered intraoperatively.

The remainder of the 6.5-hour operation was unremarkable. The infant was stable with HR $90 \mathrm{bpm}, \mathrm{BP}$ 100/40 $\mathrm{mmHg}$ and spontaneously ventilating with SpO2 $95 \%$ on room air upon conclusion of the procedure. The infant did not suffer further sequelae related to the dexmedetomidine overdose in the recovery and postoperative periods.

\section{Discussion}

We report a case of dexmedetomidine infusion administered at 60-times the intended rate for 120 minutes in a 23-month-old infant, resulting in bradycardia and hypotension. Medication errors involving infusions are invariably due to errors with dose or rate. Correctly programmed drug libraries are critical tools in preventing dose and raterelated errors. Following this incident, the pump manufacturer was notified and a widespread recall of infusion pumps was conducted for reprogramming. Besides the integration of preprogramed infusion pumps, there was no formally established system to prevent dose-related medication errors at the time of the incident. Institutional changes are critical in improving medication safety. This may involve integration of protocols that require manual double-checking by anaesthetic technicians and nurses. Increasing the number of steps in the checking process reduces the chance of a medication error.

Dexmedetomidine results in competing actions. Direct peripheral alpha-2B adrenoceptor activation initially produces sympathomimetic effects. After dexmedetomidine crosses the blood brain barrier, central alpha-2A adrenoceptors cause sympatholysis. This results in the delayed onset of overriding central sympatholytic 
effects ${ }^{3}$. We found decreasing HR and BP at high concentrations of dexmedetomidine. This differs from previously reported dexmedetomidine overdose at 60-times the intended rate in a 21-month-old infant, where cardiovascular stability was maintained without the requirement for intervention ${ }^{1}$.

Simulation was used to predict dexmedetomidine concentrations and haemodynamic response using estimates of mean arterial pressure (MAP) ${ }^{3,4}$. Observed BP changes (Figure 1a) with dexmedetomidine infusion initially followed simulation predictions (Figure 1b). Observations deviate from predicted MAP after 70 minutes, when a decrease in BP and HR were noted. The cause of these decreases is unknown. Contributing factors may include other vasoactive drugs administered, myocardial compromise due to prolonged hypertension, or direct myocardial effects due to high concentrations of dexmedetomidine ${ }^{5}$.

This case report illustrates unexpected medication error due to incorrectly preprogramed infusion pumps. The 60 -fold increase in dexmedetomidine infusion rate for 120 minutes resulted in bradycardia and hypotension. This deviated from previously reported dexmedetomidine overdose in a 21-month-old infant and simulated predictions of MAP.

\section{Learning Points}

1. Medication errors are often preventable.

2. Manual double-checking of preprogramed drug infusions is recommended to prevent dosing errors.

3. Practitioners facing dexmedetomidine overdose should be prepared to manage hypertension followed by delayed bradycardia and hypotension.

\section{Disclosures}

Ethics Approval

Not required.

Conflicts of Interest

None. 


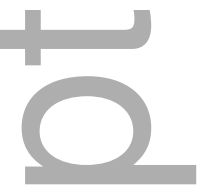

\section{References}

1. Max BA, Mason KP. Extended infusion of dexmedetomidine to an infant at sixty times the intended rate. Int J Pediatr. 2010;2010.

2. Jorden VS, Pousman RM, Sanford MM, Thorborg PA, Hutchens MP. Dexmedetomidine overdose in the perioperative setting. Ann Pharmacother. 2004;38(5):803-807.

3. Potts AL, Anderson BJ, Holford NH, Vu TC, Warman GR. Dexmedetomidine hemodynamics in children after cardiac surgery. Paediatr Anaesth. 2010;20(5):425433.

4. Li A, Yuen VM, Goulay-Dufay S, et al. Pharmacokinetic and pharmacodynamic study of intranasal and intravenous dexmedetomidine. Br J Anaesth. 2018;120(5):960-968.

5. Mason KP, Zurakowski D, Zgleszewski S, Prescilla R, Fontaine PJ, Dinardo JA. Incidence and predictors of hypertension during high-dose dexmedetomidine sedation for pediatric MRI. Paediatr Anaesth. 2010;20(6):516-523.

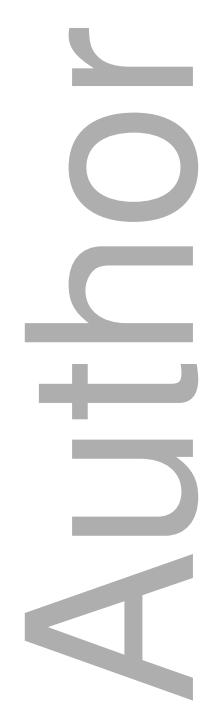

This article is protected by copyright. All rights reserved 


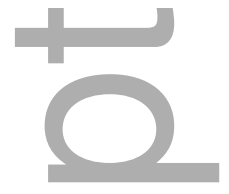

$\square$
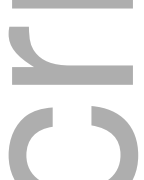

Figure Legend

Figure 1a. Changes in heart rate and blood pressure with anaesthetic regime
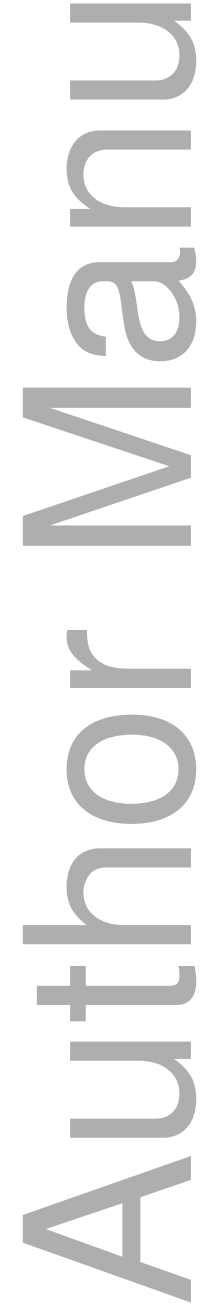

This article is protected by copyright. All rights reserved 
Figure 1a. Changes in heart rate and blood pressure with anaesthetic regime

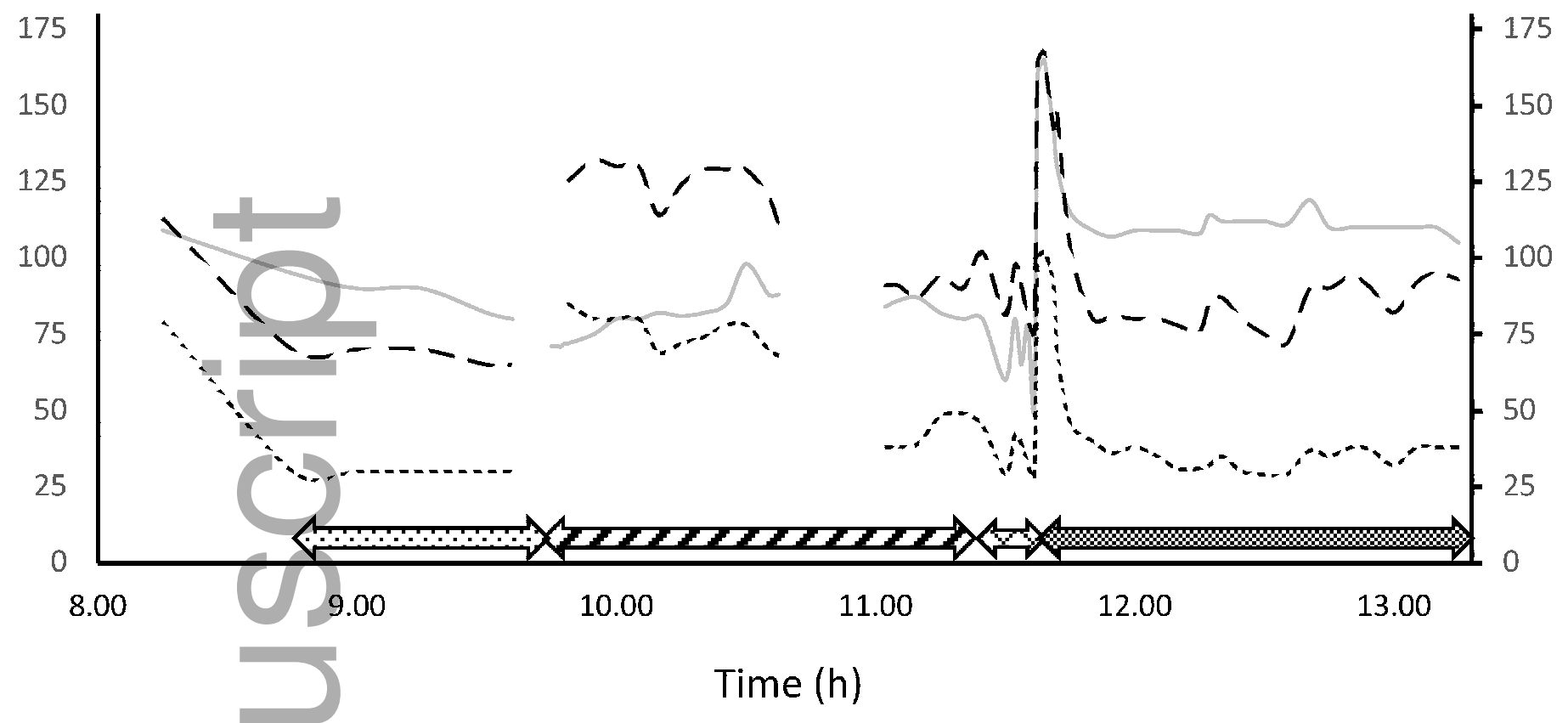

Figure 1b. Dexmedetomidine concentration and mean arterial pressure using pharmacokinetic pharmacodynamic simulation ${ }^{2,3}$

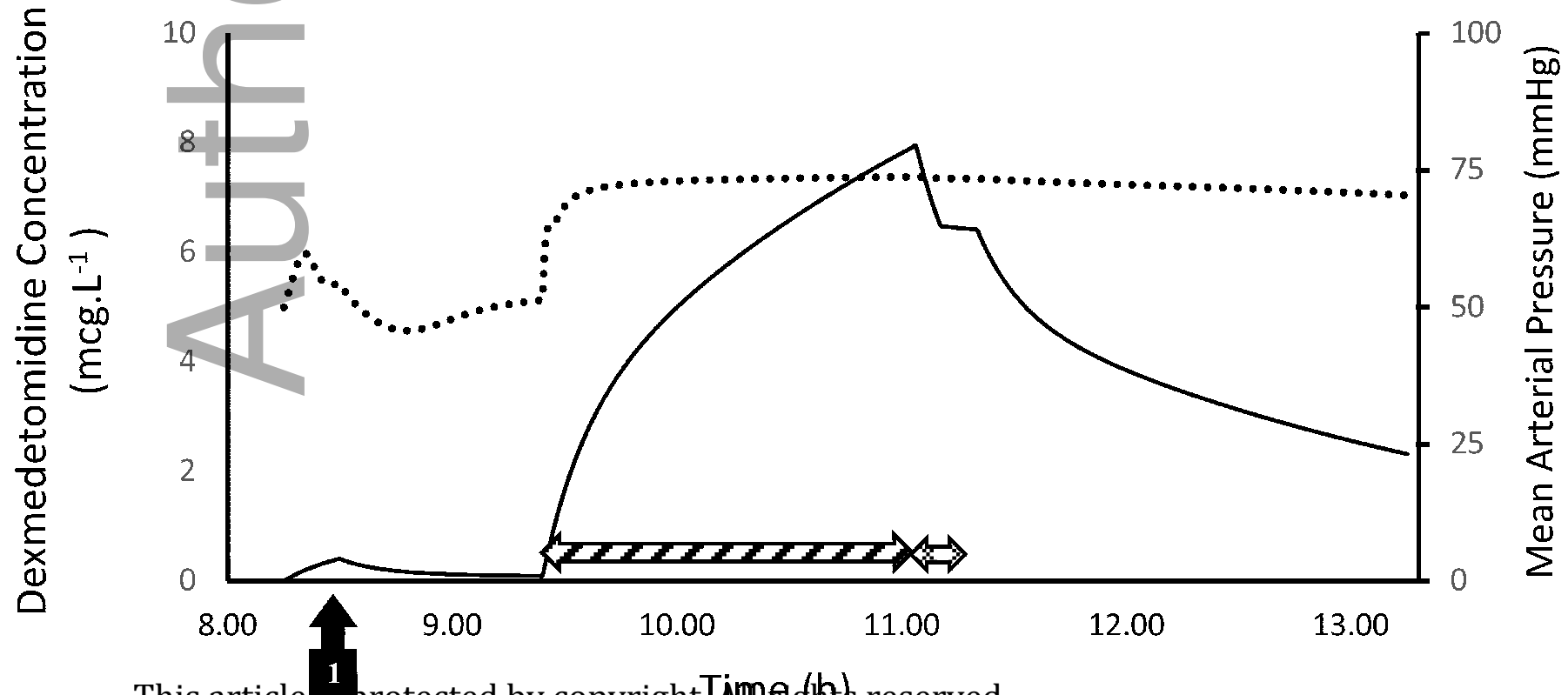

This article 1s protected by copyright. TAmeghthts reserved 


\section{University Library}

\section{- M M I E E R VA A gateway to Melbourne's research publications}

Minerva Access is the Institutional Repository of The University of Melbourne

Author/s:

Li, C;Clifford, M

Title:

Dexmedetomidine infusion overdose during anesthesia: A case report

Date:

2020-01-27

Citation:

Li, C. \& Clifford, M. (2020). Dexmedetomidine infusion overdose during anesthesia: A case report. PEDIATRIC ANESTHESIA, 30 (2), pp.191-193. https://doi.org/10.1111/pan. 13801.

Persistent Link:

http://hdl.handle.net/11343/275299 